\title{
Comparative proteomics and transcriptomics analyses of livers from two different Bos taurus breeds: "Chianina and Holstein Friesian"
}

\author{
Anna Maria Timperio ${ }^{a, *}$, Angelo D’Alessandro ${ }^{a}$, Lorraine Pariset ${ }^{b}$, Gian Maria D'Amici ${ }^{a}$, \\ Alessio Valentini ${ }^{b}$, Lello Zolla ${ }^{a}$ \\ a Dipartimento Scienze Ambientali Università "La Tuscia" Viterbo, Italy \\ bipartimento Produzione Animale Università "La Tuscia" Viterbo, Italy
}

\section{A R T I C L E I N F O}

Article history:

Received 28 July 2009

Accepted 16 September 2009

Keywords:

Holstein Friesian

Chianina

Proteomics

Liver

Microarray

Pathway analysis

\begin{abstract}
A B S T R A C T
The Holstein Friesian and Chianina cattle breeds are representative of extreme selection for milk and meat traits, respectively, with significant changes in metabolism resulting from human selection over the past centuries. In the present study, we wanted to assess whether selection for different purposes has had a measurable effect on liver metabolism through a comparison of the protein and gene expression profiles of the two breeds. We applied 2-DE in order to identify proteins which were differentially expressed in the livers of the two breeds and relate them to different liver functions. We expected to find that only a small number of proteins would be differentially expressed, due to the relatively short phylogenetic distance between these cattle breeds. Nonetheless, thirty nine differentiallyexpressed proteins were characterized between Chianina and Holstein Friesian, out of a total of $560 \pm 57$ spots that matched.

Microarray analyses evidenced the differential expression of 167 genes (148 for the Holstein Friesian and 19 for the Chianina). Despite being closely related at the genetic level, the disparity of the proteomic and transcriptomic profiles of these two breeds allows us to perform pathway analysis thus to pinpoint proteins whose expression might render the latter capable of greater milk production, or proteins involved in altered thermoregulatory ability or hormone production. On the other hand, we found proteins and gene transcripts in Chianina, not expressed in Holstein, which, upon interaction pathway analysis, were mainly involved in anabolic pathways. In brief, our integrated study provides molecular evidences to support the physiological differences between Holstein and Chianina cattle breeds.
\end{abstract}

(c) 2009 Elsevier B.V. All rights reserved.

\section{Introduction}

There is a huge amount of work currently underway on the human proteome, but little attention has been given to most animals of importance to humans. However, the importance of Bos taurus for the entire agricultural economy has prompted investigations into the fundamental mechanisms controlling animal health and productivity, including genetic analysis,

\footnotetext{
* Corresponding author. Tel.: +39 0761357630; fax: +390761357179.

E-mail address: timperio@unitus.it (A.M. Timperio).
} 